\title{
Material flows and Embodied Energy of Direct Air Capture
}

\author{
Balint Simon ${ }^{1,2}$
}

${ }^{1}$ RWTH Aachen, Chair of Operations Management, Kackertstr. 7, 52072, Aachen, Germany and 2 Institute for Energy and Environmental Research (ifeu $\mathrm{GmbH}$ ), Wilckensstr. 3 69120 Heidelberg, Germany, balint.simon@posteo.eu

Abstract: Direct air capture (DAC) is an essential nexus of $\mathrm{CO}_{2}$ chemistry and climate mitigation. Life cycle assessment (LCA) is often deployed to validate the environmental potentials of such future emerging technologies. Consequently, an increased number of ex-ante LCAs are expected in this field. However, recently a comprehensive life cycle inventory for LCA is missing from the international literature, which is essential for transparency. To fill this gap, the present paper analyses three selected DAC technologies to create an inventory for LCAs. Amine-based adsorption and -absorption, as well as, alkali-based absorption was modelled. Energy consumption of the operation, the cradle-to-gate embodied energy and sensitivity analysis based on parameter variations were carried out. The maximum energy released by the formation of $\mathrm{CO}_{2}(8.94-18.2 \mathrm{GJ} / \mathrm{t} \mathrm{CO}$ ) were also considered in the evaluation. However several studies state that DAC is a negative emission technology, its energy requirement often lies in the range or above the formation energy of $\mathrm{CO}_{2}$. Accordingly, theoretically more energy is required for the capture as can be obtained during the formation of $\mathrm{CO}_{2}$. The calculation model 
includes over 60 parameters resulting in an array of the possible energy and material requirements. The use of this wide range of figures in life cycle assessment sheds light on the real opportunities of direct air capture in future product systems. The option of varying parameters enables tailoring the calculation to a particular situation or design. In this way, the calculator offers a common base for LCA fostering the early-stage analysis of DAC technologies.

Keywords: direct air capture (DAC), $\mathrm{CO}_{2}$ amine absorption, $\mathrm{CO} 2$ adsorption, $\mathrm{CO} 2$ alkali absorption, dynamic life cycle inventory, industrial ecology 


\section{Importance of Ex-Ante Environmental Assessment of Direct Air Capture}

Closing the life cycle of carbon is a promising and efficacious method for greenhouse gas (GHG) management (Bringezu 2014), which is of importance to keep the global warming limit under

$1.5^{\circ} \mathrm{C}^{2}$. Besides, $\mathrm{CO}_{2}$ is a suitable feedstock of future fuels and chemicals ${ }^{3,4}$ even though fossil $\mathrm{CO}_{2}$-based products pose a threat to emit the physically embodied carbon at the end of their "second life".

Anthropogenic $\mathrm{CO}_{2}$ originates in point- and distributed sources exhibiting an equal share in global emissions ${ }^{5}$. It points out the importance of distributed sources in climate mitigation, even if point sources have a larger $\mathrm{CO}_{2}$ concentration than the dilute air which enables an easier emission control ${ }^{6}$.

Despite the recent technological issues, direct air capture (DAC) is capable of stopping or even mitigating the atmospheric concentration of $\mathrm{CO}_{2}{ }^{6-9}$. This statement, however, is only true on the process level of the DAC technology. The overall carbon footprint is subject to the subsequent use phase of the captured $\mathrm{CO}_{2}$, whether it remains in the technosphere or is released again. Indeed, in specific cases, the replacement of fossil energy sources with renewable resources decreases the GHG emission more efficiently than capturing the emitted $\mathrm{CO}_{2}{ }^{10}$. However, DAC suits rather for the control of diffuse than fixed point $\mathrm{CO}_{2}$ sources. On the other hand, deploying DAC for fuel synthesis or CCS processes might bring climate benefits by using low-carbon energy sources ${ }^{7,11,12}$. A further benefit of air, in contrast to the limited carbon sources of biomass, is that it represents the largest climate-friendly carbon reserve for the 
chemical and fuel industry ${ }^{4,6,13}$. Consequently, the number of environmental life cycle assessments (LCA) is rapidly growing in the field of $\mathrm{CO}_{2}$ capture and subsequent $\mathrm{CO}_{2}$ chemistry $7,11,14-16$.

Life cycle inventory (LCI) is the vital part of an LCA describing the physical input-output flows of a technology or production procedure. Accordingly, a reliable and thorough LCA requires welldocumented and complete LCl ${ }^{17}$. However, until recently, only two studies from de Jonge et al. (2019) and Deutz and Bardow (2021) deal with "cradle-to-gate/grave" LCA of DAC technology. Both are based on the available technical studies and own calculations on alkali-based absorption technology or amine-based adsorption but report fixed-value or non-reproducible inventory. Despite this sparse availability of adequate LCls, a large number of papers analyze systems including DAC $7,9,11,14,19-21$. Recent studies rely on reported figures of different available technical and techno-economic analyses ${ }^{22-27}$, but none of them reports an LCl of DAC in reproducible detail. Hence, the large variety of deployed data-sets and the lack of available deep LCl leads to lacking transparency of recent LCAs. However, several parameters of capture technologies can be obtained using thermodynamic simulation (e.g.: Aspen Plus), it is associated with software-related costs and requires the correct selection of property packages for the simulation. Thus, future LCAs of DAC require a commonly available and scalable inventory enabling more sophisticated sensitivity and uncertainty analysis of the results. To overcome the above-described issue, three different technologies were modelled in a dynamic LCl calculator based on physical and thermodynamical properties of processes and deployed materials. 
The calculator generates data on material and energy use under various capture conditions from cradle to gate including the construction phase, too. The model was also deployed for material and embodied energy analysis proving its applicability. Embodied energy is calculated on a "best-case, worst-case" basis to obtain the theoretical minimum and maximum energy required for $\mathrm{CO}_{2}$ capture. The system boundary of embodied energy comprises all primary energy consumed in life cycle stages from the exploitation of natural resources to the $\mathrm{CO}_{2}$ capture including "feedstock energy" which is physically embodied into the used fossil-based materials (polymer-plastics, rubbers, etc.) and production energies (electricity, heat). The wide range of the results supports the sophisticated analysis of the DAC systems from an industrial and ecological point of view.

Section 2 describes the selected three technologies such as (i) the adsorption process with an amine-based active material, (ii) the amine-based absorption process, and (iii) absorption processes deploying alkali-solution. The data sources and modelling parameters are also part of this section. Section 3 points out the material flow and embodied energy originates in capturing one ton of atmospheric $\mathrm{CO}_{2}$ by each technology assuming a plant capacity of $1 \mathrm{Mt} / \mathrm{a}$ (as suggested by de Jonge et al. (2019), Deutz and Bardow (2021) and Keith et al. (2018)). This section is also devoted to the discussion of the similarities and differences to the available studies of this field. Section 4 summarizes the main findings and describe the value-added for the LCA community. 


\section{Technological Options of the Analyzed DAC}

The calculation is based on free variables that can be adjusted to a particular situation or design, such as ambient temperature or pressure, air humidity, capture capacity of the active material, pressure drop, different thermodynamic constants, or the efficiency of mechanical parts (e.g. fluid pumps). These variables define the work-parameters, among others, the required air input, the ad- or absorbed amount of $\mathrm{CO}_{2}$ per hour, sorbent requirements (makeup and initial requirement), and the energy consumption of air moving, heat exchangers, heating devices, or fluid pumps.

One amine-based adsorption and two absorption methods were selected as these two types of technologies constitute $72 \%$ of the recent research and patenting activities ${ }^{28}$. The following sub-sections describe the train of thought, how the energy and material requirements of adsorption on modified amines (cf. Wurzbacher (2015)), absorption in a special amine-water solution (cf. Ohle $(2009,2010)$ ) and alkali-basis solution are calculated (cf. Keith and Mahmoudkhani (2012), Keith et al. (2015)).

The calculation scheme and the results are validated by comparison to the most recent publications reporting energy consumption ${ }^{16,18,23,26,34}$. Requirements of civil engineering are also calculated, however, material and mechanical work demand of construction can vary on a wide range, since it hardly depends on the particular conditions of the construction site, for example, bearing capacity of the soil ${ }^{35,36}$. 


\subsection{The Maximum Obtainable Energy Assigned to $\mathrm{CO}_{2}$-Emissions}

Primary energy deployed from the production stage to capturing the atmospheric $\mathrm{CO}_{2}$ is defined as embodied energy (cf. Section 1). Worst-case and best-case scenarios are deduced from the most efficient and at least efficient energy- or material conversion processes. Basic datasets for the estimation of embodied energy of the process inputs, such as cement, steel, gravel, soil work, different plastics, thermal- and electrical energy was taken from the Ecoinvent database (Version 3.5) ${ }^{37}$.

Furthermore, a reference value was calculated to indicate the break-even point from which the capture uses more energy than the theoretically maximal gain from $\mathrm{CO}_{2}$ emission. Methane exhibits one of the most higher lower heating values (LHV) amid carbon-containing fuels. Consequently, it can be used to calculate the above-mentioned limiting value. The conversion factor of methane to carbon dioxide is $\sim 2.75 \mathrm{~kg} \mathrm{CO}_{2} / \mathrm{kg} \mathrm{CH}_{4}$. Thus, $50 \mathrm{MJ} / \mathrm{kg}$ LHV of methane results in $\sim 18,182 \mathrm{MJ}$ energy development per $\mathrm{kg} \mathrm{CO} 2$ released from a perfect burning process. This value encompasses the formation of water, too. A similar value, but without water formation, can be calculated by using the enthalpy of formation from constituent elements (elementary $\mathrm{C}$ and $\mathrm{O}_{2}$ ) resulting in $8,942 \mathrm{MJ} / \mathrm{t} \mathrm{CO}$ formed. Accordingly, technologies requiring energy between 8.94-18.2 GJ/t CO 2 are in an energetically grey zone, while using more than 18.2 GJ/t $\mathrm{CO}_{2}$ represents a disadvantage from the energy efficiency point of view.

The calculator has also been tested by a sensitivity analysis. The following crucial parameters were analysed on a particular range with a lognormal distribution: captured fraction (net capture efficiency of the plant - efficacy), pressure drop, the capture efficiency of the active 
material (sorption capacity), the efficiency of heat recovery in terms of required external heating after heat exchange. It supports the identification of technical bottlenecks.

\subsection{The Background Data}

Different sorbent active materials and support materials are also modelled to estimate embodied energy of the capturing process ${ }^{3,22,38-42}$. Specific heat capacities were used to estimate the minimal thermal energy demand of production and later the desorption ${ }^{31,43-45}$. Synthesis recipes and energy requirements of material synthesis are based on literature ${ }^{16,46-54}$. Embodied energy, namely the whole energy demand from cradle to gate was taken from the Ecoinvent database cut-off version $3.5^{37}$.

\subsection{Adsorption}

The current adsorption model is based on the TVS (temperature vacuum swing adsorption) method. Working conditions and civil engineering demand are based on general physical parameters, equations. Some values were taken from different reports of ClimeWorks-DAC projects and were adjusted to the current situation ${ }^{16,21,22,29,55-58}$.

Requirements of civil engineering were reported in Schreiber et al. (2020), Lozanovski (2019) and Repond (2017). Deutz and Bardow (2021) also considered the impacts of construction, although only the resulting $\mathrm{CO}_{2 \mathrm{e}} \mathrm{GHG}$ emission was reported. The DAC device is mounted on four columns several meters distance from the soil. Supporting the large weight of adsorption machinery, a raft type foundation was selected based on the potential load of each pillar ${ }^{35,36}$. 


\subsection{Absorption in Organic Solution (washing column)}

Absorption in amine-based solutions, similarly to the adsorption by amines, provides the advantage of the low thermal intensity of desorption, in contrast to the high thermal requirement of calcination processes $4,24,59,60$.

The current model considers the GenosorbN (GS) (poly(methyldiglycol)amine) based vertical counterflow washing system taken from the PhD Thesis of A. Ohle (2009) ${ }^{30,31}$. GS is an aminecontaining low vapor pressure detergent, consequently, it might have low toxicity and unlimitedly miscible with water ${ }^{30}$. A solution of GS in 50 wt.\% is assumed to be used for $\mathrm{CO}_{2}$ capture purposes, as it leads to the lowest moisture absorption from the air ${ }^{30}$. Different elements were also adapted to the model, such as the design of sorption columns ${ }^{24,25,61-63}$, sorbent recovery ${ }^{64,65}$ or the captured fraction per pass ${ }^{23,24,66}$. Several system elements had to be also scaled (cf. Simon et al. (2016), and Piccinno et al. (2016)).

The civil engineering demand is based on the assumption that the system is constituted by packed bed columns with relatively large diameters. It enables a low surface load per square meter. Thus, a simple slab foundation also meets the required bearing capacity ${ }^{69}$. The whole 1 Mt/a plant requires at least $\sim 250$ capture units (combination of above-described absorptiondesorption columns), which is in accordance with Mazzotti et al. (2013). Packaging properties were taken from the specific producer ${ }^{70}$, while the plate heat exchanger with an average flow rate of $150 \mathrm{~m}^{3} / \mathrm{h}$ was based also on the information of the manufacturer ${ }^{71}$. 


\subsection{Absorption in Inorganic (alkali) Solution}

Carbon dioxide exhibits an acidic character. Hence, chemical absorption in alkali-basis is proved to be a possible way of DAC $23-25,32,33,60,66,72-74$.

The recent model describes the $\mathrm{CO}_{2}$ capture by $\mathrm{NaOH}$ and Ti-based recovery reported and patented by Keith and Mahmoudkhani ${ }^{32,33}$. It is divided into the following three parts:

1. Direct air contactor to capture ambient $\mathrm{CO}_{2} 23,63,72,74-76$

2. Crystallization of $\mathrm{Na}_{2} \mathrm{CO}_{3}$ from the pregnant solution for causticizing in fluidized bed reactor $(\mathrm{FBR})^{32,77,78}$

3. Leaching recovery of $\mathrm{NaOH}$ using sodium-titanate $32,79,80$

Keith et al. (2018) and de Jonge et al. (2019) report an inventory for capture system, however, the secondary loop of salt recovery is excluded from those datasets. While Liu et al. (2020) assess the carbon intensity of an alkali absorption-based DAC-to-fuel system, however, the study lacks a detailed $\mathrm{LCl}$ and the analysis rather based on GHG values from EEIO LCA (environmentally extended input-output LCA). The model of the current air contactor is based on patents and reports from the last decade $33,63,72,75,76,81-83$. The carbonate recovery is modelled by a system of crystallizers, fluid storage tanks and FBR taken from different reports and adopted to the current situation ${ }^{77,84-87}$.

\section{Assessment of the Energy and Material Flows}

Material and Energy flows of the construction phase and the use phase, furthermore, embodied energy of the whole process serve a solid basis to evaluate the above-described 
three DAC-system from an industrial and ecological point of view. The findings are contrasted to the latest know-how of this field.

\subsection{Required Sorbent and Energy Flows in the Use Phase}

Figure 1 represents the distribution of energy and sorbent consumption by different variations of freely adjustable parameters (cf.Section 2). The literature data of the thermal energy for the absorption and adsorption varies between 4.0-11 GJ/t CO $2,3.2-7.2 \mathrm{GJ} / \mathrm{t} \mathrm{CO}$, respectively, while electricity demand ranges between $125-1200 \mathrm{kWh} / \mathrm{t} \mathrm{CO} 2,200-1000 \mathrm{kWh} / \mathrm{t} \mathrm{CO}$, respectively (cf. Fig. 1 part $A$ and $B)^{60,63,72,73,75,83,83,88-92}$. The calculated thermal energy requirement moves on a broader range than the literature data, between $2.6 \mathrm{GJ} / \mathrm{t} \mathrm{CO}$ and $17 \mathrm{GJ} / \mathrm{t} \mathrm{CO}$, while the electricity consumption shows a narrower distribution between $83-903 \mathrm{kWh} / \mathrm{t} \mathrm{CO}_{2}$. 

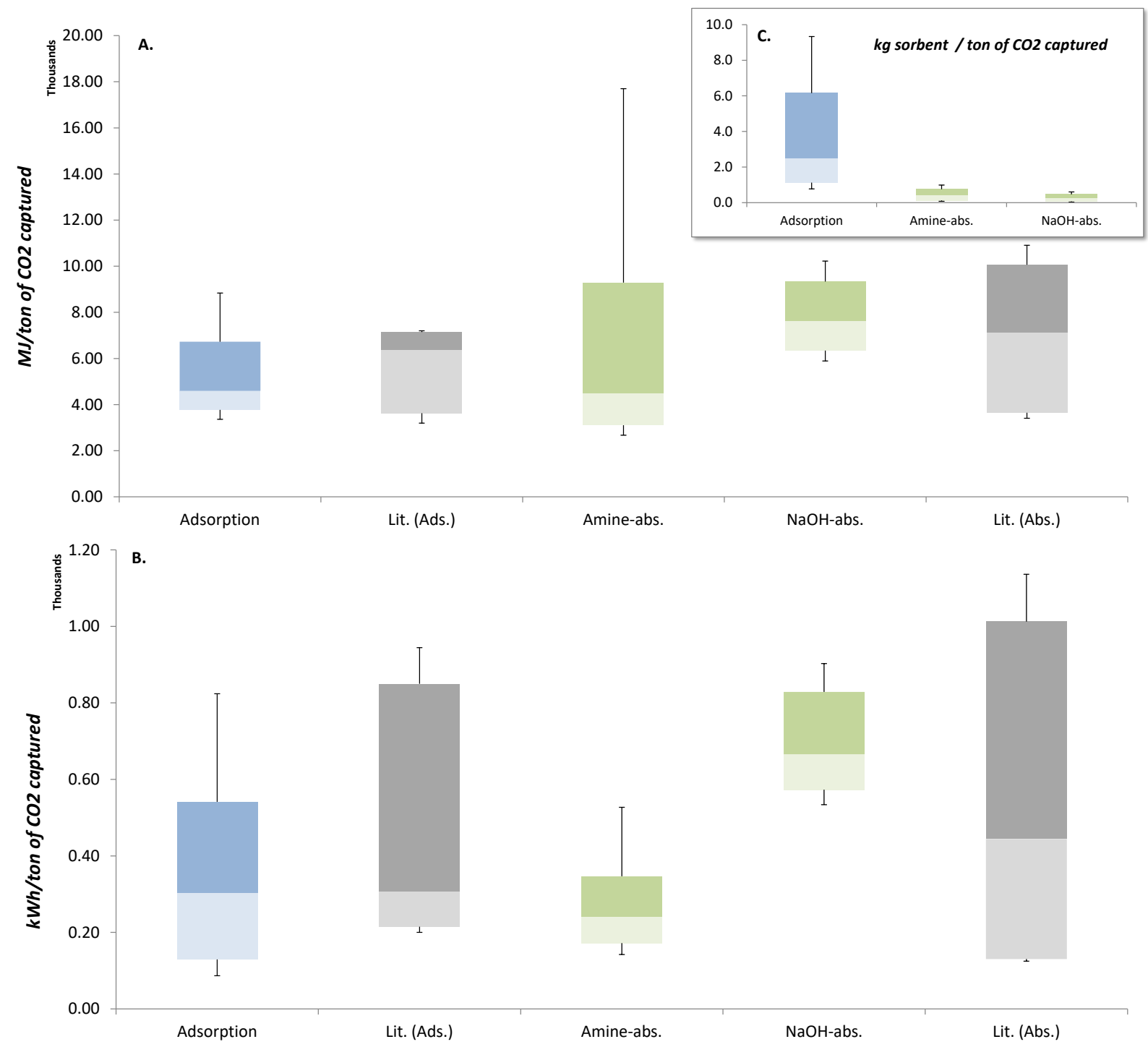

Figure 1 Electrical and thermal energy demand of capturing one ton of $\mathrm{CO} 2$ (mean value, upper and lower $95 \%$; min. and max. values). Blue bars represent the adsorption, green is for absorption while grey bars stand for literature values. Calculated values are based on 1000 iterations, while literature values were taken from up to 18 reports and papers

The calculated thermal energy requirement of adsorption lies close to the values found in the

literature. Amine-absorption shows the significantly broader distribution and higher values than

$\mathrm{NaOH}$-absorption and the $95^{\text {th }}$ percentile of both types range on the same scale as the

literature values $24,60,63,66,72,75,83,88,89,93$. The high peak of thermal requirement calculated for the

amine-absorption can be explained by the specific heat capacity of sorbent fluid (measured to 
be $\left.\left.3.6 \mathrm{~kJ} /\left(\mathrm{mol}^{*} \mathrm{~K}\right)\right)^{30}\right)$ resulting in considerable thermal energy demand in the desorption phase even at moderate temperatures $\left(\sim 70^{\circ} \mathrm{C}\right)$. However, heat for amine-desorption can be fed by low-quality energy, such as waste heat, the implementation of similar water/amine mixture based sorbents with high specific heat capacity might face the significant obstacle of lowquality heat availability. The heat requirement of $\mathrm{NaOH}$-absorption moves on a narrower range as amine-based absorption, but retrieving $\mathrm{CO}_{2}$ from carbonates occurs at high temperature by $850-900^{\circ} \mathrm{C}$. It represents a substantial difference to low-temperature desorption and confines the application to the availability of natural gas. Noting the substantial differences between the quality of thermal energies, it is worth conducting an exergy analysis pursuing the fate of dissipating thermal energy and cumulative energy demand.

The mean value of the calculated electricity consumption for adsorption overlaps with the literature although wider $95^{\text {th }}$ percentile values have been found based on other reports ${ }^{21,58,88-}$ 92. A higher upper percentile suggests more conservative assumptions applied in the literature. Sensitivity analysis explains this deviation (Section 3.4). The calculated electricity consumption for absorption processes shows a more concentrated picture as it can be found in the literature. The higher values of $\mathrm{NaOH}$-absorption, compared to the amine counterpart, can be explained by the system setting of thermally controlled crystallization requiring the significant cooling of large sorbent amounts to obtain solid carbonates. The further energy-intensive procedure is the extensive differences in the potential energy of sorbent fluid regarding the case of $20 \mathrm{~m}$ tall washing columns. 
Figure $1 / C$ depicts the variations of the active material requirements depending on process parameters. The literature is unanimous in the required amount of sorbent, which is found to be $3.75 \mathrm{~kg}$ active material per ton of $\mathrm{CO} 2$ captured ${ }^{16,21,34,58}$. The current adsorption model, however, results in values ranging on a wide scale $(0.77-9.55 \mathrm{~kg}$ sorbent $/ \mathrm{t} \mathrm{CO} 2$ with a median of 2.44), in contrast to the low deviation of amine- and $\mathrm{NaOH}$-absorption. Different parameters affect the sorbent demand. For example, adsorption is modelled with a higher decomposition rate of sorbent reported for $\sim 0.01 \%$ per cycle ${ }^{56}$, compared to the calculated considerably lower deterioration of amine in fluid support up to $\sim 0.0008 \%$ per cycle ${ }^{94,95}$ and $\mathrm{NaOH}$ loss in air contactor by $\sim 0.235 \mathrm{mg} / \mathrm{m} 3$ air throughput ${ }^{81}$. The sorption capacity of GenosorbN is calculated for $7.7 \mathrm{mg} \mathrm{CO} 2 / \mathrm{g}$ sorbent in each cycle while adsorption can capture $32.1 \mathrm{mg} \mathrm{CO} 2 / \mathrm{g}$ sorbent in the base case 22,30 , which can also lead to different sorbent consumptions. Eliminating this theoretical discrepancy of decomposition and sorption capacity by deploying the same factors for both technologies, the amine-absorption requires up to $150 \mathrm{~kg}$ sorbent make-up per ton $\mathrm{CO}_{2}$ on average. However, using a lower sorbent flow rate in the washing column, according to the recommendations of packing producers down to $0.2 \mathrm{~m}^{3} / \mathrm{m}^{2 *} \mathrm{~h}$ instead of the originally implemented $8.5 \mathrm{~m}^{3} / \mathrm{m}^{2 *} \mathrm{~h}^{30}$, the sorbent make-up moderates in the same level as of the adsorption ( $1.0-10 \mathrm{~kg}$ sorbent $\left./ \mathrm{t} \mathrm{CO}_{2}\right)$.

\subsection{Average Energy and Material Flows}

The following section gives an insight into material and energy flows at the use phase of DAC (see Figures 2-4). The Sankey diagrams inform about the complexity and weighted relations of required materials and energies. 
Since LCA-based studies report only degradation-related material requirements, the capital amount stays hidden which represents magnitudes higher volumes of required material. For example, in Figure 2 can be seen the proportion of sorbent make-up to the sorbent required for operating. Up to 11 kilotons of sorbent materials (50:50 active-:support material) are required by a $1 \mathrm{Mt} / \mathrm{a}$ DAC-plant and 500kg sorbent material decomposes (250 kg amine active material) in every hour of the operation. A vast amount of wastewater develops equals to the daily production of a smaller village.

A $1 \mathrm{Mt} / \mathrm{a}$ plant requires up to 1000 DAC units described in SI (cf. Schreiber et al. (2020) and Deutz and Bardow (2021)).

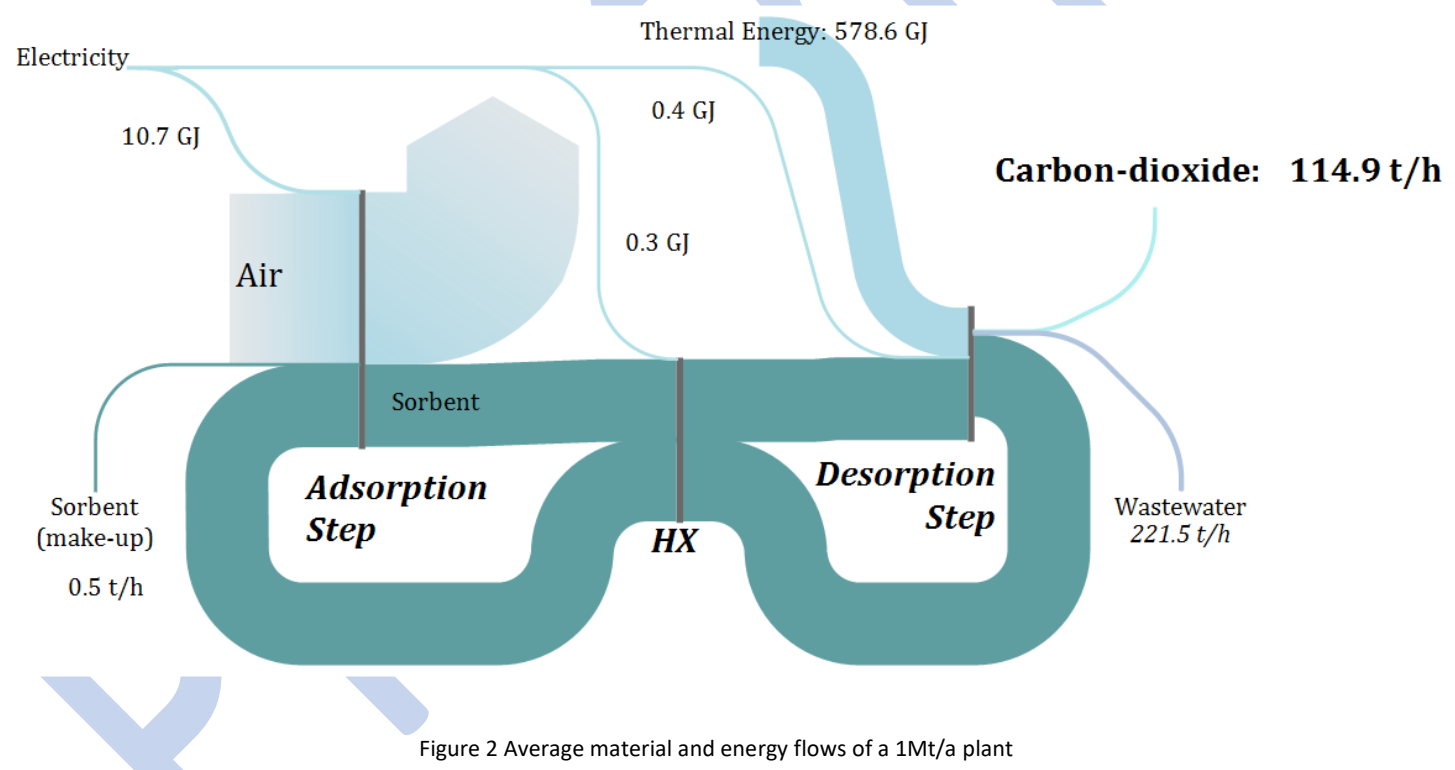

Figure 3 depicts the average material and energy flows of an amine-absorption divided into an absorption column, a heat exchanger $(\mathrm{HX})$ and the desorption column. The sorbent fluid trickles down in a packed bed column while the air moves bottom-up. More than $127 \mathrm{~m}^{3} / \mathrm{h}$ washing fluid has to be moved on average in each washing unit. A $1 \mathrm{Mt} / \mathrm{a}$ plant requires up to 250 of such washing columns (cf. ${ }^{25}$ ) The pregnant sorbent is pumped into a plate heat exchanger to 
utilize the "waste heat" of regenerated sorbent from the desorption column. The average electricity consumption is lower than at the adsorption while heat requirement is double.

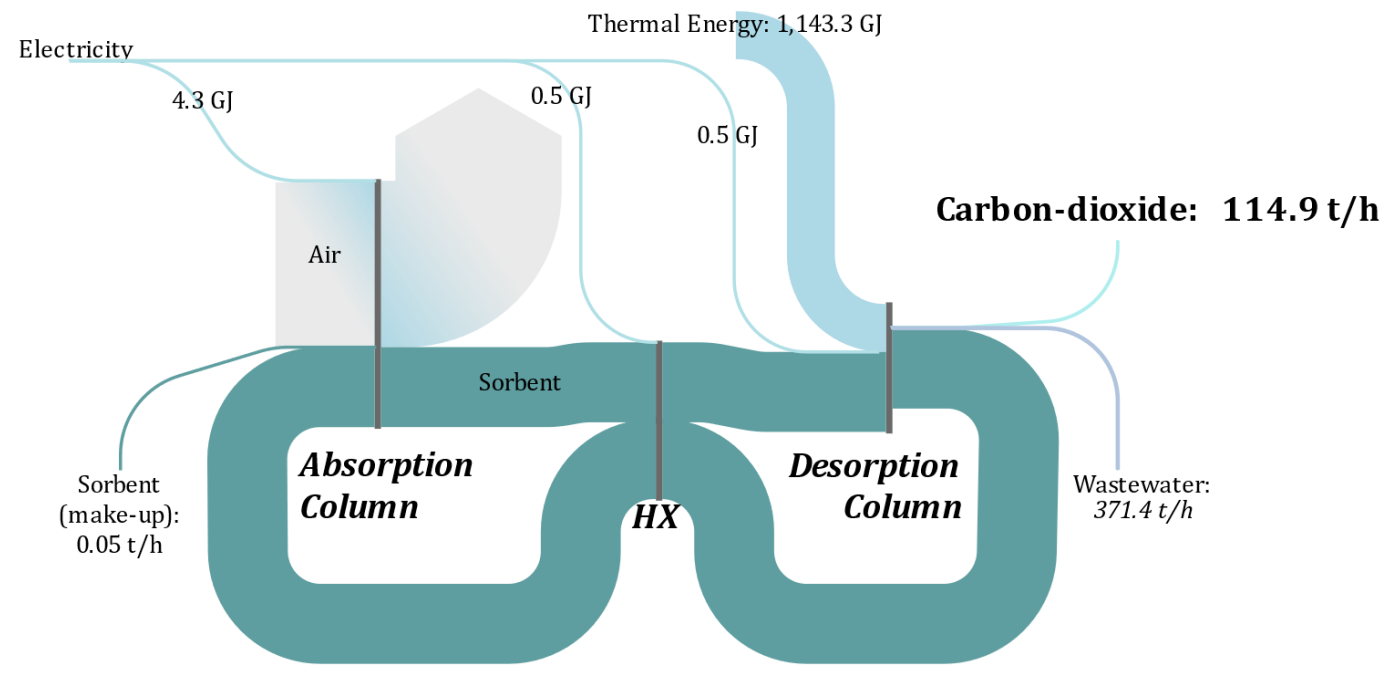

Figure 3 Material and energy flow of absorption operation (amine-based washing fluid, counterflow vertical column)

The model of $\mathrm{NaOH}$-absorption consists of the following two process stages (cf. Fig. 4):

- Absorption in a cross-flow air contactor where $\mathrm{NaOH}$ reacts with the atmospheric $\mathrm{CO}_{2}$ into $\mathrm{Na}_{2} \mathrm{CO}_{3}$ (see Figure 4) $23,33,76$

- Regeneration of the $\mathrm{NaOH}$-solution and retrieving $\mathrm{CO}_{2}$ by causticization according to the Ti-method which is a complex procedure as follows. Sodium-decahydrate is precipitated after air washing followed by a resolution in warm water to eliminate crystal water from $\mathrm{Na}_{2} \mathrm{CO}_{3} * 10 \mathrm{H}_{2} \mathrm{O}$. After resolution, $\mathrm{NaOH}$ is leached by adding sodium-pentatitanate. The formed sodium-trititanate and sodium-carbonate are crystallized in a subsequent process and conveyed to a fluidized bed reactor to retrieve captured $\mathrm{CO}_{2}$ and sodium- 
pentatitanate (Crytallisataion, Leaching and Fluidized bed reactor /FBR/ in Figure 4) $32,75,82$

The sorbent make-up is subtle because it is modelled to occur only by the drifting effect into the air. Wastewater production is not modelled as water evaporates or is taken up during air contacting under particular conditions (calculated in accordance to ${ }^{60}$. However, in several cases, a remarkable amount of water make-up is required (cf. Figure 4). Electricity demand is typically high due to the energy-intensive thermal swing (cooling) for crystallization where up to $6000 \mathrm{~m}^{3}$ solution is chilled by $5-20^{\circ} \mathrm{C}^{32,60}$ and remarkable pumping work (cf. section 3.1).

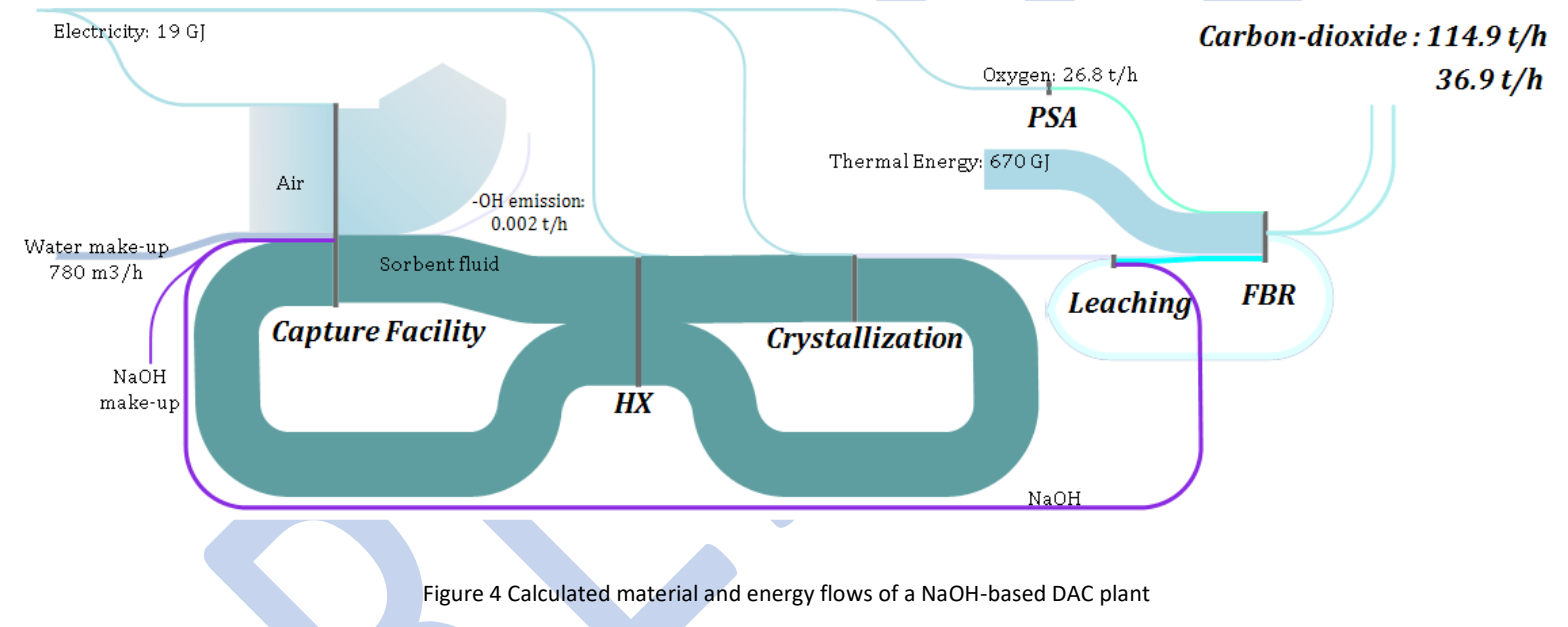

\subsection{Life cycle embodied energy}

Table 1 informs about embodied energy of each technology divided into best and worst cases.

The values are broken down to the environmental cost of civil engineering and the impacts of the operation ("running cost"). Each value is on the same order of magnitude, however, adsorption is calculated to demand 1.5-2 times more energy for foundations than the counterpart technologies. It can be explained by the higher need for a DAC unit for a $1 \mathrm{Mt} / \mathrm{a}$ plant, furthermore, amine-absorption requires less foundation due to the assumedly lower load 
factor of the wide absorption columns. Assuming the material requirement of the machinery is a quite demanding task.

Lozanovski (2019) and Schreiber et al. (2020) report numbers for machinery consumption of an adsorption DAC unit, Deutz and Bardow (2021) analyses a similar system too. However, contrary to the previous two, Deutz and Bardow (2021) deploys an alternative lifetime without describing the exact inventory of construction. Thus, obtaining machinery $\mathrm{LCl}$ for the current calculation tool was encumbered due to this minuscule discrepancy in underlying literature. The information on adsorption was more elaborated, accordingly, Table 1 describes significantly higher embodied energy for adsorption machinery than for absorption. Without aluminum and copper, which are non-available information for absorption, the figures of adsorption decrease to the same range as the counterpart technologies.

However, the construction of the plant is an important life cycle stage, less significant from the embodied energy point of view, as DAC is typically an energy-intensive process. Consequently, impacts of operation, due to the purchased energy, considerably outweigh the "capital costs". The sorbent demand from Figure $1 / C$ also manifests in the embodied energy. These values exhibit uncertainty as described in Section 3.1. Namely, the higher decomposition rate of amine-absorption might lead to remarkably higher embodied energy. Air fan is the most important machinery part, especially at the adsorption, where the air moving is the main consumer of electricity by up to $95 \%$ share in embodied energy. Fluid pump becomes an important part of the absorption technologies, as column height determines the potential 
energy to overcome by fluid pumping. For example, the sorbent fluid has to be pumped up to $20 \mathrm{~m}$ high in the case of $\mathrm{NaOH}$-absorption.

Sorbent recovery takes $9.5 \%$ of the entire electricity input of amine-absorption encompassing the evaporation of surplus absorbed moisture, accordingly, managing the uptake of water by the washing fluid plays a remarkable role in electricity consumption. Similarly in $\mathrm{NaOH}-$ absorption, the recovery loop requires up to $40 \%$ of the entire embodied energy, namely cooling the pregnant solution before crystallization and generating nearly pure oxygen for oxycombustion in FBR. 
Table 1 "Cradle to gate" life cycle embodied energy of each technology normalized to 1 ton of captured atmospheric $\mathrm{CO} 2$

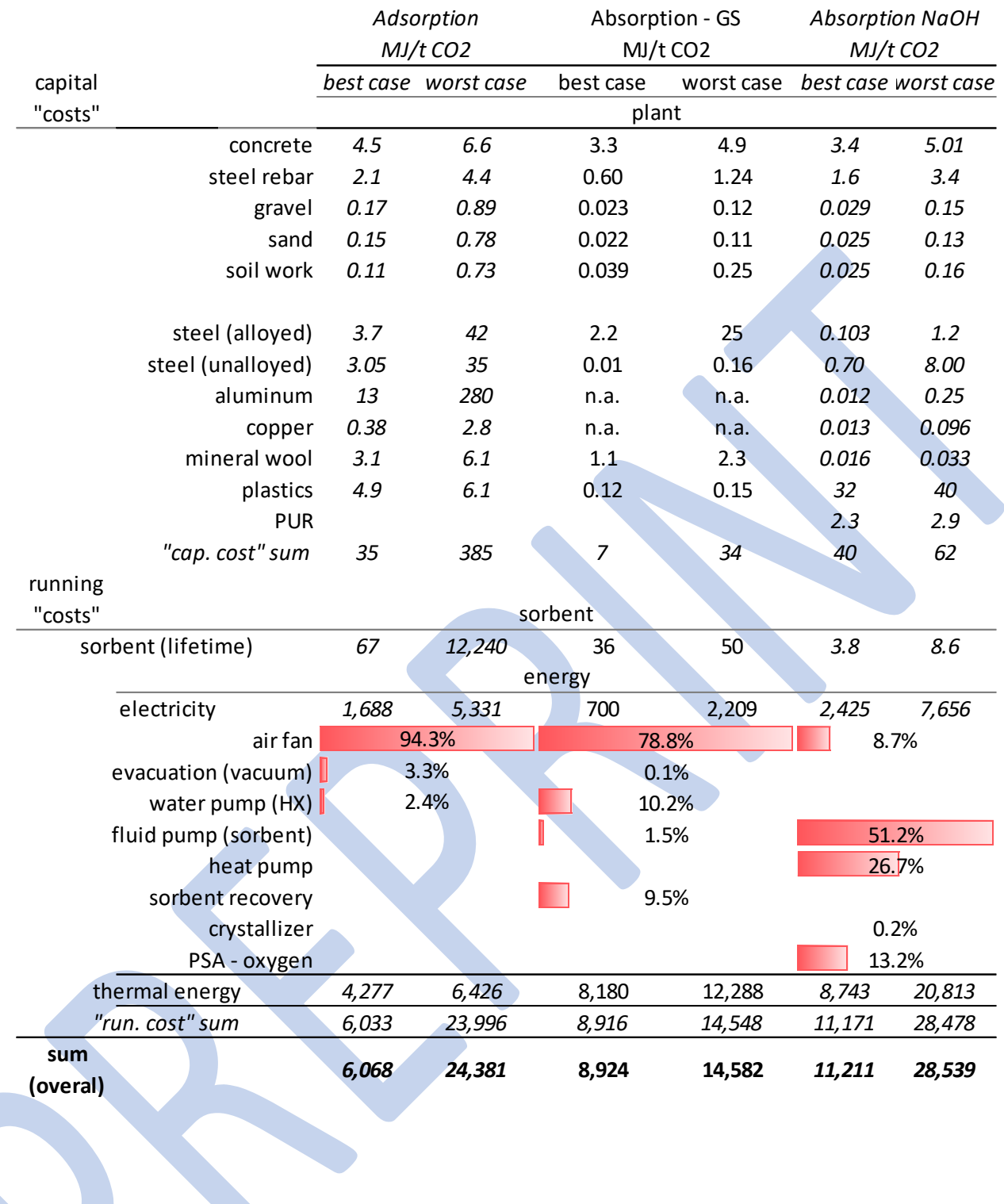

\subsection{Bottlenecks and Pivots (Sensitivity Analysis)}

Capture efficacy shows significant sensitivity, especially in the case of $\mathrm{NaOH}$-absorption (see

Figure 5 and Figure 6). The higher sensitivity of the mentioned technology in the heat demand

(Figure 6) can be explained by the thermally intensive "desorption" procedure.

Pressure-drop represents a limiting factor as a large volume of diluted air is required for the capture. DAC is typically working directly with ambient air containing solid particles such as 
dust, sand or different organic components, leaves or insects. Deposits of such solid contaminations increase the pressure drop in the adsorption device by fouling the capillaries of the sorbent. It might result in rapidly decreasing capture efficiency and growing sorbent demand. Thus, it causes larger deviances in electricity consumption.

Likewise, the washing fluid in absorption might be contaminated by ambient air leading to unwanted chemical-physical reactions, and resulting in an increasing make-up demand. Accordingly, deploying an air treatment regime is worth considering, with regard to the tradeoff between electricity demand and efficient sorbent usage.

Pressure-drop was also identified as a bottleneck in electricity consumption in a vertical flow absorption column. It depends on gas and fluid velocity defined by the packing material ${ }^{24,25,96}$. This structural constraint can be tackled by a diagonal contactor where the air streams horizontally ${ }^{76,81}$. Accordingly, the diagonal flow design might significantly mitigate the air fanrelated energy requirements (see Figure 5, the lower sensitivity of $\mathrm{NaOH}$-absorption in pressure drop).

Such "diagonal constructs" enable to build of a higher stacked tower as absorption columns. The gross height of the so-built absorption facility represents a trade-off between the fluid pumping work and land occupation, as a lower built facility needs less pumping work but uses a larger land surface. It is worth considering if land occupation becomes a sensitive factor in planning (cf. sensitivity of pumping efficiency in Figure 5).

A further sensitive parameter is the air fan efficiency affecting adsorption more remarkable as absorption (cf. share of fan in embodied energy, Table 1). Careful selection of industrial heat 
pump for $\mathrm{NaOH}$-absorption system is crucial due to the large share in the overall energy consumption (cf. Table 1)

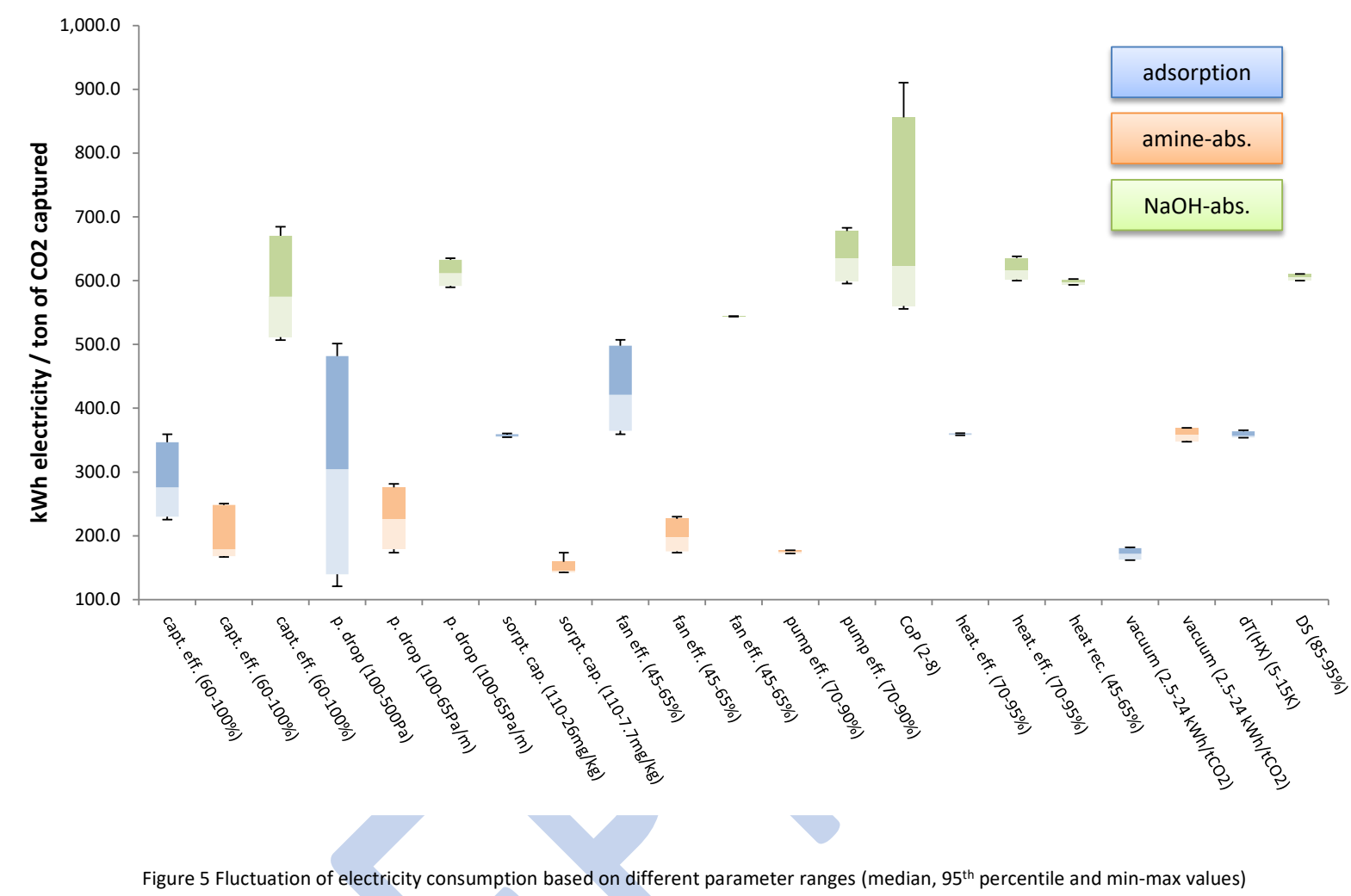

The efficiency of heating devices is rather important in absorption processes. Thus, a welldesigned insulation system is of high importance to moderate heat requirements. Nevertheless, the efficiency of heat exchange between desorption and pregnant sorbent is found to be vital for moderate heat management in amine absorption (see Figure 6). 


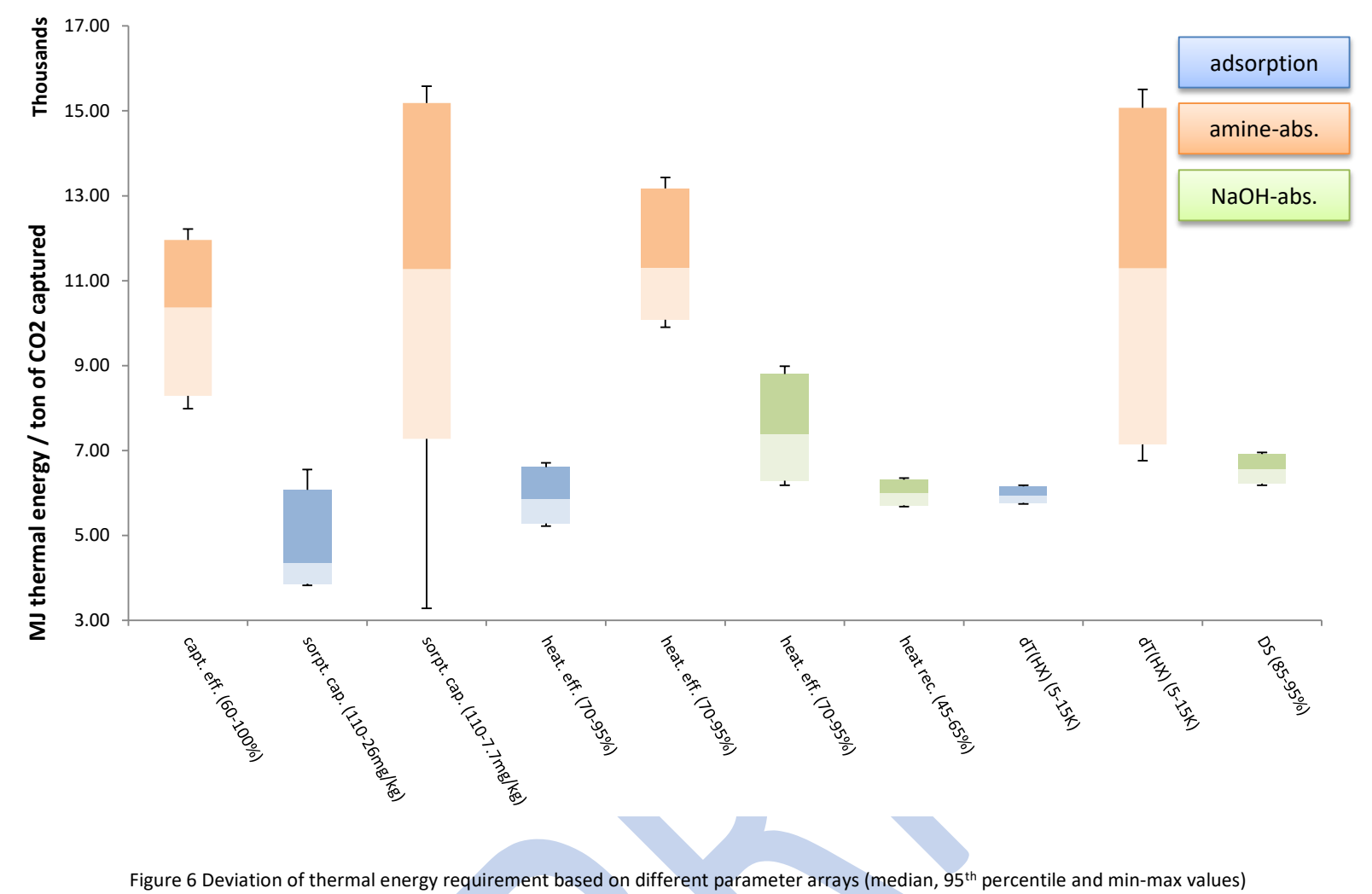

\subsection{Operability of DAC calculator}

Schreiber et al. (2020) take into account anionic resin for modelling sorbent material based on Ecoinvent 3.5. It results in $3.18 \mathrm{~kg} \mathrm{CO}_{2 \mathrm{e}} / \mathrm{kg}$ resin ${ }^{37}$, while the same figure for the calculated aminosilane ranges between $4.76-13.59 \mathrm{~kg} \mathrm{CO} 2 \mathrm{e} / \mathrm{kg}$ sorbent (depending on material degradation rate and sorbent capture capacity). The required energy is set for $500 \mathrm{kWh}$ and 5.4 GJ for electricity and thermal energy, respectively ${ }^{21}$. However, this value can vary between $80-$ $800 \mathrm{kWh}$ and 3.0-9.0 GJ due to varying operation parameters. This wide difference can affect the result considerably making the Power-to-fuel production environmentally less attractive. Liu et al. (2020) found that $139 \mathrm{~g} \mathrm{CO}_{2 \mathrm{e}} / \mathrm{kWh}_{\mathrm{e}}$ is required for synthetic fuel production to outperform the GHG intensity of conventional diesel fuel. However, the electricity consumption of alkali-based absorption can deviate by $\pm 35-40 \%$. The so calculated wide array of GHG 
emissions from electricity can drastically impact the carbon footprint of DAC-based fuel. Accordingly, in some cases, the range of $102-139 \mathrm{~g} \mathrm{CO}_{2 \mathrm{e}} / \mathrm{kWh}_{\mathrm{e}}$ is required for providing environmental benefits against fossil-based diesel.

As from Figures 5 and 6 can be deduced, electrical energy is the main energy source in the ab/adsorption phase, while thermal energy is deployed for desorption and causticization, but to a larger extent. Thus, access to different sources of thermal energy limits the overall process. For example, future diverse political decisions such as phasing out fossil coal-fired thermal power plants from the national energy mix can lead to lacking availability of low-value heat to meet DAC capacities. It might rebound in deploying high-quality energy sources (electricity or natural gas) (cf. ${ }^{21}$. However, using power-to-heat based on renewable electricity promises a viable option for desorption, whether it is direct heating or heat pumps ${ }^{97,98}$. Furthermore, converting solar energy directly to heat using solar collectors can also fuel the desorption process ${ }^{99}$. Even though renewables offer a low-carbon energy source for DAC, the availability is still constrained in time and space. Different load levelling and peak shaving methods (e.g. battery storage) might enable using more renewables at a low price and low cumulative energy demand (cf. ${ }^{7,100,101}$ ). Hence, the realization of a large-scale DAC project might require international cooperation placing DAC and other components close to renewable sources (cf. Power-to-X export from North Africa to Europe) ${ }^{102}$. Considering the above-discussed capacity constraints and energy availability for DAC purposes, further systematic analyses will answer the question, how DAC can appropriately be tailored 
and embedded in a particular system obtaining low environmental burdens. The known parameter sensitivity provides essential information for further planning. However, DAC is a technically feasible and promising negative emission technology, the first inter-model comparison reveals long-term threats and opportunities of large-scale implementation combined with sequestration (DACS). DACS might help by reducing the climate mitigation related costs, despite the remarkable energy requirement ${ }^{103}$. Indeed, another study says that global restoration of cultivated lands by $15 \%$ would sequester up to $299 \mathrm{Gt}$ of atmospheric $\mathrm{CO}_{2}{ }^{104}$. To capture the same amount by DAC, based on current calculated values, requires at least 40,000 TWh of electricity. It corresponds to $150 \%$ of the global production in $2019^{105}$

It has to be noted, that the above-mentioned electricity is only a part of the entire energy demand of DAC. It was found that all modelled DAC technology exhibits embodied energy in the calculated grey zone (8.94-18.2 GJ/tCO $)$. However, selecting the appropriate sorbent material for adsorption can decrease the energy demand below this value. Table 1 points out that thermal energy represents the bottleneck of embodied energy with the highest demand on primary energy sources, thus, contributes significantly to reaching the energetically unwanted interval. It raises an issue to consider, whether the direct implementation of energy-efficient and renewable-based technologies bring more benefits for climate mitigation (cf. ${ }^{10}$ ), while recultivation is more effective in $\mathrm{CO}_{2}$-sequestration (cf. ${ }^{103,104}$ ). This energy issue might be tackled by using passive air contacting by harnessing the wind ${ }^{106}$. However, it might significantly lower the efficacy of the capture, since the so-called "artificial 
trees" can only produce $\mathrm{CO}_{2}$-rich gas with $4-5 \%$ vol. $\% \mathrm{CO}_{2}$ and active aeration help avoid idle time.

\section{Summary}

As $\mathrm{CO}_{2}$-chemistry and DAC appear more and more frequently in the context of a low-carbon future ${ }^{4,13}$, the number of science-based environmental assessments increases to analyse the validity of future technologies. To meet this demand, the current paper provides a transparent calculation method of LCI for selected DAC technologies and enlightens the parameters representing a bottleneck or even playing a pivotal role in energy and material consumption. The calculation tables in the SI represent a data generation tool for LCA of product systems encompassing atmospheric carbon capture. There is also an option to develop and extend the tables.

The calculator delivers values lie in the same order of magnitude with the latest research and measured data of this field (cf. Repond (2017), de Jonge et al. (2019), Keith et al. (2018), E. Bajamundi et al. (2019) and Deutz and Bardow (2021)) This close correlation presumes the correctness of the calculation paths. In addition, the calculator provides detailed parameter analysis, which is not available in the most recent literature. It supports the calculation of an appropriate range of environmental impacts enabling a more sophisticated evaluation of the analysed system and careful future planning.

Summarizing the results, the thermal energy requirement contributes extensively to the overall energy consumption of DAC followed by the electricity of forced air moving as vast volumes of air are required to treat for each ton of $\mathrm{CO}_{2}$ captured. Fluid pumps become more significant in 
fluid-based sorption. It makes the height of the absorption column an important factor, enabling significant energy saving by appropriate design. However, lower built air contactors with less pumping work requirement result in larger land occupation (cf. Section 3.3). Construction demand exhibits negligible figures in the overall life cycle even though the type and measures of foundation depending on the on-site conditions. Thus, this calculation is highly uncertain without knowing the particular circumstances.

An important finding is that the embodied energy analysis shows vast energy demand in all DAC cases. In this way, capturing one unit of atmospheric $\mathrm{CO}_{2}$ requires more primary energy as it can be obtained by the formation of the same amount of $\mathrm{CO}_{2}$. Implementing sorbents with high sorption capacity and developing technologies with low thermal energy demand represent a suitable direction toward energetically optimized DAC.

The current DAC model delivers valid results without using complex software-based simulations. It represents a general basis for future integrated assessment models and LCA studies in the field of DAC and $\mathrm{CO}_{2}$-chemistry supporting more transparent results. The model can be developed toward including more details of material losses or a new design of sorbent recovery in absorption systems.

\section{FUNDING INFORMATION}

Special thanks to the Ministry of Economics, Innovation, Digitalization, and Energy of the State of North Rhine-Westphalia for the support through the project SCI4climate.NRW (EFO-001D). 
Furthermore, this study was partly supported by the German Federal Ministry of Education and Research through the projects Kopernikus-P2X (03SFK2WO).

\section{REFERENCES}

1 S. Bringezu, Journal of Industrial Ecology, 2014, 18, 327-340.

2 J. Tollefson, Nature, 2018, 562, 172.

3 A. Goeppert, M. Czaun, J.-P. Jones, G. K. S. Prakash and G. A. Olah, Chem. Soc. Rev., 2014, 43, 7995-8048.

4 G. A. Olah, G. K. S. Prakash and A. Goeppert, J. Am. Chem. Soc., 2011, 133, 12881-12898.

5 G. Blanco, R. Gerlagh, S. Suh, J. Barrett, H. C. de Coninck, C. F. D. Morejon, R. Mathur, N. Nakicenovic, A. O. Ahenkorah, J. Pan, H. Pathak, J. Rice, R. Richels, S. J. Smith, D. I. Stern, F. L. Toth and Zhou Peter, in Climate Change 2014: Mitigation of Climate Change. Contribution of Working Group III to the Fifth Assessment Report of the Intergovernmental Panel on Climate Change, Cambridge University Press, Cambridge and New York, 2014, vol. 5AR, pp. 351-411.

6 N. von der Assen, L. J. Müller, A. Steingrube, P. Voll and A. Bardow, Environ. Sci. Technol., 2016, 50, 1093-1101.

7 H. A. Daggash, C. F. Patzschke, C. F. Heuberger, L. Zhu, K. Hellgardt, P. S. Fennell, A. N. Bhave, A. Bardow and N. M. Dowell, Sustainable Energy Fuels, 2018, 2, 1153-1169.

8 K. S. Lackner, P. Grimes and H. J. Ziock, in 24th International Technical Conference on Coal Utilization and Fuel Systems, Clearwater, FL (US), 1999.

9 P. Viebahn, A. Scholz and O. Zelt, Energies, 2019, 12, 3443.

10 M. Z. Jacobson, Energy Environ. Sci., 2019, 12, 3567-3574.

11 C. M. Liu, N. K. Sandhu, S. T. McCoy and J. A. Bergerson, Sustainable Energy Fuels, 2020, 4, 3129-3142.

12 W. J. Sagues, S. Park, H. Jameel and D. L. Sanchez, Sustainable Energy Fuels, 2019, 3, 3135-3146.

13 A. Goeppert, M. Czaun, G. K. S. Prakash and G. A. Olah, Energy Environ. Sci., 2012, 5, $7833-7853$.

14 S. Deutz, D. Bongartz, B. Heuser, A. Kätelhön, L. S. Langenhorst, A. Omari, M. Walters, J. Klankermayer, W. Leitner, A. Mitsos, S. Pischinger and A. Bardow, Energy Environ. Sci., 2018, 11, 331-343.

15 V. Dieterich, A. Buttler, A. Hanel, H. Spliethoff and S. Fendt, Energy Environ. Sci., 2020, 13, 3207-3252.

16 S. Deutz and A. Bardow, Nature Energy, 2021, 6, 203-213.

17 N. von der Assen, J. Jung and A. Bardow, Energy Environ. Sci., 2013, 6, 2721-2734.

18 M. M. J. de Jonge, J. Daemen, J. M. Loriaux, Z. J. N. Steinmann and M. A. J. Huijbregts, International Journal of Greenhouse Gas Control, 2019, 80, 25-31. 
19 W. Hoppe, N. Thonemann and S. Bringezu, Journal of Industrial Ecology, 2017, n/a-n/a.

20 N. Thonemann and M. Pizzol, Energy Environ. Sci., 2019, 12, 2253-2263.

21 A. Schreiber, A. Peschel, B. Hentschel and P. Zapp, Front. Energy Res., , DOI:10.3389/fenrg.2020.533850.

22 C. Gebald, J. A. Wurzbacher, P. Tingaut, T. Zimmermann and A. Steinfeld, Environ. Sci. Technol., 2011, 45, 9101-9108.

23 D. W. Keith, G. Holmes, D. S. Angelo and K. Heidel, Joule, 2018, 2, 1573-1594.

24 R. Baciocchi, G. Storti and M. Mazzotti, Chemical Engineering and Processing: Process Intensification, 2006, 45, 1047-1058.

25 M. Mazzotti, R. Baciocchi, M. J. Desmond and R. H. Socolow, Climatic Change, 2013, 118, 119-135.

26 C. J. E. Bajamundi, J. Koponen, V. Ruuskanen, J. Elfving, A. Kosonen, J. Kauppinen and J. Ahola, Journal of CO2 Utilization, 2019, 30, 232-239.

27 D. Krekel, R. C. Samsun, R. Peters and D. Stolten, Applied Energy, 2018, 218 , 361-381.

28 B. Li, Y. Duan, D. Luebke and B. Morreale, Applied Energy, 2013, 102, 1439-1447.

29 J. A. Wurzbacher, Doctoral Thesis, ETH Zurich, 2015.

30 A. Ohle, Doctoral Thesis, Technical University Dresden, 2009.

31 A. Ohle, Chemie Ingenieur Technik, 2010, 82, 666-672.

32 Carbon Engineering Ltd, US8119091 B2, 2012.

33 Carbon Engineering Ltd, US9095813 B2, 2015.

34 N. Repond, 2017.

35 R. W. Day, in Foundation Engineering Handbook: Design and Construction with the 2009 International Building Code, Second Edition, McGraw-Hill Education, 2010.

36 J. A. Hemsley, Design applications of raft foundations, Thomas Telford Publishing, 2000.

37 G. Wernet, C. Bauer, B. Steubing, J. Reinhard, E. Moreno-Ruiz and B. Weidema, Int J Life Cycle Assess, 2016, 21, 1218-1230.

38 H. Azarabadi and K. S. Lackner, Applied Energy, 2019, 250, 959-975.

39 S. Choi, M. L. Gray and C. W. Jones, ChemSusChem, 2011, 4, 628-635.

40 J. A. Wurzbacher, C. Gebald and A. Steinfeld, Energy Environ. Sci., 2011, 4, 3584-3592.

41 H. Zhang, A. Goeppert, G. K. S. Prakash and G. Olah, RSC Advances, 2015, 5, 5255052562.

42 S. H. Pang, R. P. Lively and C. W. Jones, ChemSusChem, 2018, 11, 2628-2637.

43 J. Cakstins, Journal of the Department of Chemical and Environmental Engineering: University of Nottingham.

44 M. W. Jr. Chase, J. Phys. Chem. Ref. Data, 1998, 9, 1961.

45 C. Qi, S. Hou, J. Lu, W. Xue and K. Sun, Holzforschung, 2020, 74, 1099-1112.

46 A. R. Tedeschi and R. A. Wilson, 2010 WM Symposia, Phoenix, AZ (United States), 2010.

47 B. W. Hackett, CEP Magazine.

48 JRC, Reference Document on Best Available Techniques for the Manufacture of Large Volume Inorganic Chemicals - Solids and Others industry, European IPPC Bureau, Ispra, Italy, 2007.

49 G. N. Ambaryan, M. S. Vlaskin, E. I. Shkolnikov and A. Z. Zhuk, J. Phys.: Conf. Ser., 2020, 1687, 012030.

50 H. Barthel, L. Rösch and J. Weis, in Organosilicon Chemistry II, John Wiley \& Sons, Ltd, 1995, pp. 761-778. 
51 Boustead, Eco-profiles of the European Plastics Industry: SODIUM HYDROXIDE, PlasticsEurope, 2005.

52 China, CN104262173A, 2015.

53 China, CN104174336A, 2014.

54 United States, US6423858B1, 2002.

55 Climeworks Ag, WO2015185434 A1, 2015.

56 C. Gebald, J. A. Wurzbacher, P. Tingaut and A. Steinfeld, Environ. Sci. Technol., 2013, 47, $10063-10070$.

57 J. A. Wurzbacher, C. Gebald, S. Brunner and A. Steinfeld, Chemical Engineering Journal, 2016, 283, 1329-1338.

58 A. Lozanovski, presented in part at the 17th International Conference on Carbon Dioxide Utilization, Aachen, June, 2019.

59 C.-H. Yu, C.-H. Huang and C.-S. Tan, Aerosol and Air Quality Research, 2012, 12, 745769.

60 R. Socolow, M. Desmond, R. Aines, J. Blackstock, O. Bolland, T. Kaarsberg, N. Lewis, M. Mazzotti, A. Pfeffer, K. Sawyer, J. Siirola, B. Smit and J. Wilcox, Direct Air Capture of CO2 with Chemicals: A Technology Assessment for the APS Panel on Public Affairs, American Physical Society, 2011.

61 K. Andersson, B. Jeong and H. Jang, Journal of International Maritime Safety, Environmental Affairs, and Shipping, 2020, 4, 162-176.

62 H. Stripple and Y. Zhang, Scrubbers: Closing the loop, IVL Swedish Environmental Research Institute, 2018.

63 M. Mahmoudkhani, K. R. Heidel, J. C. Ferreira, D. W. Keith and R. S. Cherry, Energy Procedia, 2009, 1, 1535-1542.

64 B. W. Tleimat and M. C. Tleimat, Reduced Energy Consumption Evaporator for Use in Desalting Impaired Waters, Water Reuse Technology, 75 Ina Court, Alamo, CA 94507, 1995.

65 B. W. Tleimat and M. C. Tleimat, Desalination, 1996, 107, 111-119.

66 F. Zeman, Environ. Sci. Technol., 2007, 41, 7558-7563.

67 B. Simon, K. Bachtin, A. Kiliç, B. Amor and M. Weil, Integrated Environmental Assessment and Management, 2016, 12, 465-477.

68 F. Piccinno, R. Hischier, S. Seeger and C. Som, Journal of Cleaner Production, 2016, 135, 1085-1097.

69 J. D. Schroeder, Cylindrical Aboveground Storage Tank Foundation Requirements, Steel Tank Institute, Minnesota, 2001.

70 MML, 2021.

71 Onda, 2021.

72 J. K. Stolaroff, D. W. Keith and G. V. Lowry, Environ. Sci. Technol., 2008, 42, 2728-2735.

73 K. Z. House, A. C. Baclig, M. Ranjan, E. A. Nierop, J. Wilcox and H. J. Herzog, Proc Natl Acad Sci USA, 2011, 108, 20428.

74 D. W. Keith, Science, 2009, 325, 1654-1655.

75 M. Mahmoudkhani and D. W. Keith, International Journal of Greenhouse Gas Control, 2009, 3, 376-384.

76 G. Holmes and D. W. Keith, Phil. Trans. R. Soc. A, 2012, 370, 4380-4403.

77 A. Giesen, H. Erwee, R. Wilson, M. Botha and S. Fourie, Pretoria, South Africa, 2009, p. 6. 
78 W. Dimoplan, Chemical Engineeers' Calculation and Shortcut Desctop, 1978, 11-11.

79 I. Nohlgren, H. Theliander, Q. Zhuang and A. R. P. V. Heiningen, The Canadian Journal of Chemical Engineering, 2000, 78, 529-539.

80 D. M. Ruthven, S. Farooq and K. S. Knaebel, Pressure Swing Adsorption, Wiley, 1993.

81 G. Holmes, K. Nold, T. Walsh, K. Heidel, M. A. Henderson, J. Ritchie, P. Klavins, A. Singh and D. W. Keith, Energy Procedia, 2013, 37, 6079-6095.

82 D. Keith, K. Heidel and R. Cherry, in Geo-Engineering Climate Change: Environmental Necessity or Pandora's Box?, Cambridge University Press, Cambridge, 2010, p. 332.

83 D. W. Keith, M. Ha-Duong and J. K. Stolaroff, Climatic Change, 2006, 74, 17-45.

84 H.-J. Althaus, R. Hischier, M. Osses, A. Primas, S. Hellweg, N. Jungbluth and M. Chudacoff, Life Cycle Inventories of Chemicals, Econinvent Centre, Dübendorf, 2007.

85 J. G. Turner, in Design applications of raft foundations, Thomas Telford Publishing, 2000, pp. 185-203.

86 R. Frischknecht, P. Suter, U. Bollens, M. Ciot, L. Ciseri, G. Doka, R. Hischier and A. Martin, Ökoinventare von Energiesystemen Grundlagen für den ökologischen Vergleich von Energiesystemen und den Einbezug von Energiesystemen in Ökobilanzen für die Schweiz, 1996.

87 K. Myöhänen, R. Diego, R. Kuivalainen and T. Hyppänen, Energy Procedia, 2017, 114, 589-599.

88 K. S. Lackner, Eur. Phys. J. Spec. Top., 2009, 176, 93-106.

89 D. W. F. Brilman and R. Veneman, Energy Procedia, 2013, 37, 6070-6078.

90 T. Wang, J. Liu, M. Fang and Z. Luo, Energy Procedia, 2013, 37, 6096-6104.

91 W. Zhang, H. Liu, C. Sun, T. C. Drage and C. E. Snape, Chemical Engineering Science, 2014, 116, 306-316.

92 A. R. Kulkarni and D. S. Sholl, Ind. Eng. Chem. Res., 2012, 51, 8631-8645.

93 F. Zeman, Environ. Sci. Technol., 2014, 48, 11730-11735.

94 A. Heydari-Gorji and A. Sayari, Ind. Eng. Chem. Res., 2012, 51, 6887-6894.

95 J. Davis and G. Rochelle, Energy Procedia, 2009, 1, 327-333.

96 L. S. Tan, A. M. Shariff, K. K. Lau and M. A. Bustam, Journal of Industrial and Engineering Chemistry, 2012, 18, 1874-1883.

97 IRENA, Innovation landscape brief: Renewable power-to-heat, International Renewable Energy Agency, Abu Dhabi, 2019.

98 A. Sternberg and A. Bardow, Energy Environ. Sci., 2015, 8, 389-400.

99 S. C. Bhatia, in Advanced Renewable Energy Systems, ed. S. C. Bhatia, Woodhead Publishing India, 2014, pp. 94-143.

100 M. Baumann, B. Zimmermann, H. Dura, B. Simon and M. Weil, 2013, pp. 87-92.

101 B. Zimmermann, M. Baumann, B. Simon, H. Dura and M. Weil, IEEE, Alghero, Italy, 2013, pp. 248-253.

102 M. Boulakhbar, B. Lebrouhi, T. Kousksou, S. Smouh, A. Jamil, M. Maaroufi and M. Zazi, Journal of Energy Storage, 2020, 32, 101806.

103 G. Realmonte, L. Drouet, A. Gambhir, J. Glynn, A. Hawkes, A. C. Köberle and M. Tavoni, Nature Communications, 2019, 10, 3277.

104B. B. N. Strassburg, A. Iribarrem, H. L. Beyer, C. L. Cordeiro, R. Crouzeilles, C. C. Jakovac, A. Braga Junqueira, E. Lacerda, A. E. Latawiec, A. Balmford, T. M. Brooks, S. H. M. Butchart, R. L. Chazdon, K.-H. Erb, P. Brancalion, G. Buchanan, D. Cooper, S. Díaz, P. F. 
Donald, V. Kapos, D. Leclère, L. Miles, M. Obersteiner, C. Plutzar, C. A. de M.

Scaramuzza, F. R. Scarano and P. Visconti, Nature, 2020, 1-6.

105 BP, Statistical Review of World Energy 2020, BP p.l.c., London, 2020.

106 K. S. Lackner, in Geoengineering of the Climate System, 2014, pp. 80-104.

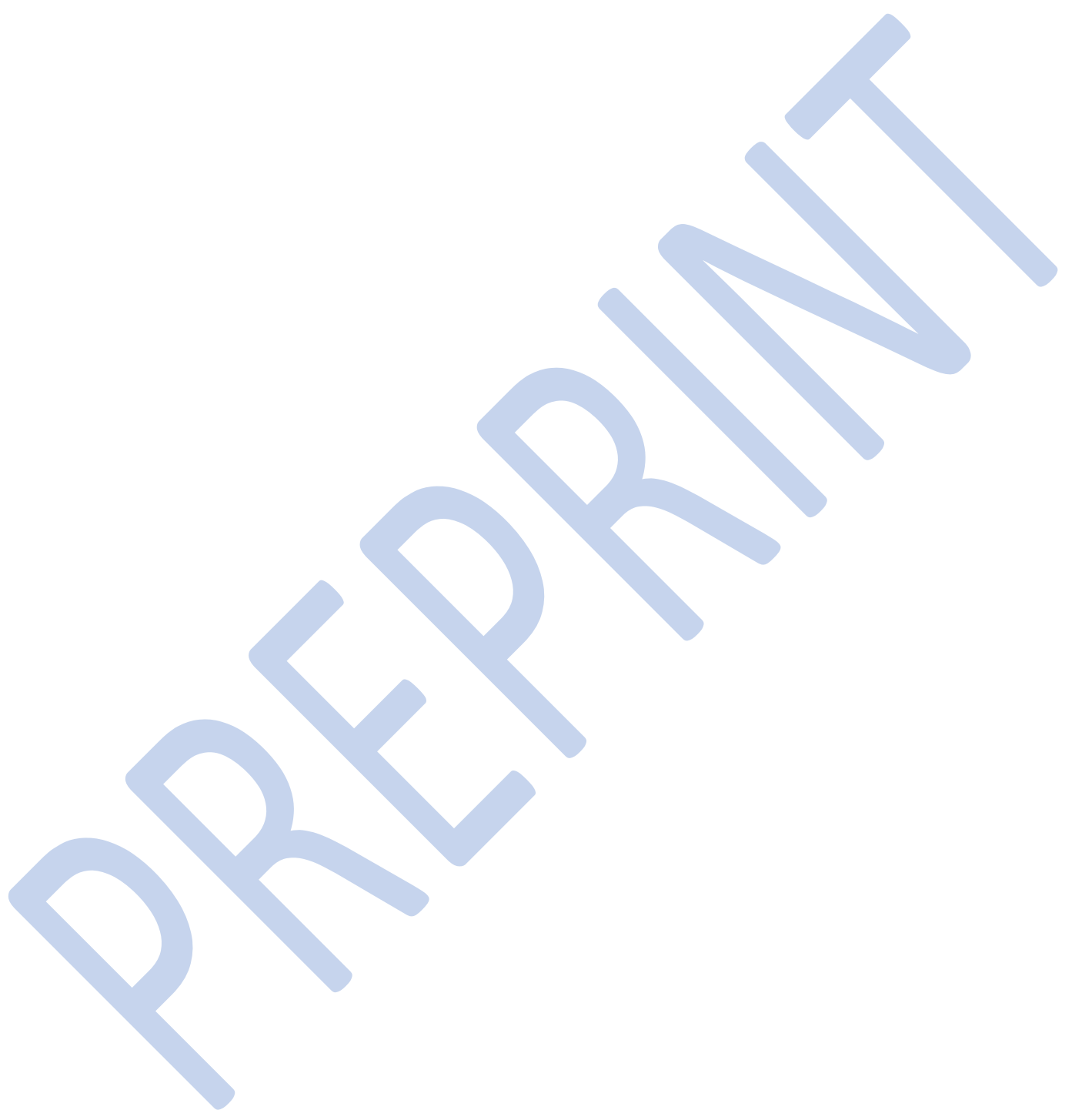

